\title{
Observations on the Mechanisms of
}

\section{Glucosuria during Glucose Loads}

\section{in Normal and Nondiabetic Subjects}

\author{
John J. McPhaul, JR. and John J. Simonattis \\ From the Department of Medicine, Wilford Hall United States Air Force Hospital, \\ Aerospace Medical Division, Air Force Systems Command, \\ Lackland Air Force Base, Texas 78236
}

A B S T RAC T The study of 14 normal young men by glucose titration procedures has defined the magnitude of splay in this population, differing from previously reported data in its unexpected deviation from the line of theoretic unity high on the titration curve. Compared to these normal subjects, a group of glucosuric men could be divided into two subclasses, those with normal maximal rate of glucose reabsorption $\left(\mathrm{Tm}_{\mathrm{G}}\right)$ and those with subnormal $\mathrm{Tm}_{\mathrm{G}}$, both with comparably abnormal splay. Most consistent glucosurics fall into the latter group. Nephritic patients studied were not such a homogeneous group in terms of age and sex, but did manifest an abnormal splay during their titration curves in most cases. They also demonstrated a greater than normal reabsorptive rate of glucose per unit measured glomerular filtration rate. It is concluded that renal glucosuria must be defined not only in terms of the concept of $\mathrm{Tm}_{\mathrm{G}}$ but also by deviation of the glucose titration curve expressing an unusual degree of splay. The latter is presumed, as has been suggested by others, to be a characteristic of nonhomogeneity of glucose handling units in the kidney. This seems subject to exaggeration in

Major McPhaul's present address is the Department of Experimental Pathology, Scripps Clinic and Research Foundation, La Jolla, Calif. 90237.

Major Simonaitis' present address is the Malcolm Grow United States Air Force Hospital, Andrews Air Force Base, Md. 21605.

Received for publication 20 April 1967 and in revised form 4 October 1967. the adaptations which accompany chronic renal disease.

\section{INTRODUCTION}

Marble (1) has proposed stringent criteria for the definition and identification of classic or true renal glucosuria, and has estimated its incidence at approximately $0.1-0.4 \%$ of the general population. Nevertheless, reports from surveys of military recruits at induction centers, factory workers, and a variety of pathophysiological states associated with disordered metabolism, such as pregnancy and nephritis, have suggested that nondiabetic glucosuria may be encountered relatively frequently (2-5).

The mechanisms by which either occasional or consistent glucosuria is initiated have not been investigated systematically in man. Studies of saturation kinetics of renal tubular transport, first by Shannon and Fisher (6) in dogs and later by Smith (7) in humans, have suggested that glucose is actively reabsorbed in the mammalian nephron and that a limiting rate of transport, $\mathrm{Tm}_{\mathrm{G}}$, can be defined (8). Analysis of these studies and subsequent investigations by others $(9,10)$ have led to the hypothesis that the deviation from a linear relationship between the filtered and reabsorbed glucose (splay) encountered during glucose titrations is representative of a nonhomogeneity of nephron populations comprising the kidney.

Review of published material indicated a dearth 
of information which compares glucose titrations in normal young men against men with glucosuria $(7,11)$. In an effort to define similarities and differences in the renal handling of glucose loads by normal young men, men with glucosuria, and patients with chronic nephritis, a series of glucose titrations was performed on representative groups of subjects.

In addition to confirming the magnitude of the maximum reabsorptive rate of glucose in normal men, these studies indicated a lesser titration splay than has been described before. On the other hand, glucosuric men, either with true renal glucosuria or a sporadic variety of inconsistent nondiabetic glucosuria, seem to posses the common characteristic of an abnormal splay of their titration curves. This latter characteristic is also manifest in many patients with nephritis, with and without renal insufficiency.

\section{METHODS}

Glucose titrations were performed in 14 normal young male volunteers between the ages of 17 and $28 \mathrm{yr}$; all were screened by history, physical examination, and urinalysis, and found free of obvious disease; none had glucosuria. Two other subjects underwent determinations of $\mathrm{Tm}_{\mathrm{G}}$ without titration. These 16 subjects com- prise the control group. The glucosuric group of patients were 14 servicemen referred to us for evaluation of demonstrated glucosuria, after screening examinations had found them otherwise free of disease. All had at least two normal glucose tolerance tests with $100 \mathrm{~g}$ glucose loads by mouth. Certain characteristics of these subjects are tabulated in Table II. Consistent glucosuria is defined as glucosuria occurring on most occasions; rare urinalyses were glucose free. Occasional glucosuria represented uncommon and inconsistent detection of glucosuria discovered on more than one occasion. The third group studied were 10 biopsy-proven nephritic patients who underwent investigation in the course of general evaluation, either in the outpatient clinic or on the renal ward at Wilford Hall United States Air Force Hospital. All had proteinuria, abnormal urinary sediments, and history of renal disease. All but case 10 were normotensive; all were studied off medication and had normal glucose tolerance tests. Relevant clinical data from this group of patients are displayed in Table III.

Glucose titrations were performed in the forenoon while the subjects were fasting, and during water hydration by mouth after all subjects were duly informed and gave their consent. Urine was collected through an indwelling rubber catheter directly into graduated cylinders. After a suitable priming dose of inulin was administered intravenously, maintenance inulin in normal saline was given by infusion pump at a rate of $3.15 \mathrm{ml} /$ min to maintain a plasma level between 20 and $30 \mathrm{mg} /$ $100 \mathrm{ml}$. After collection of control period specimens,

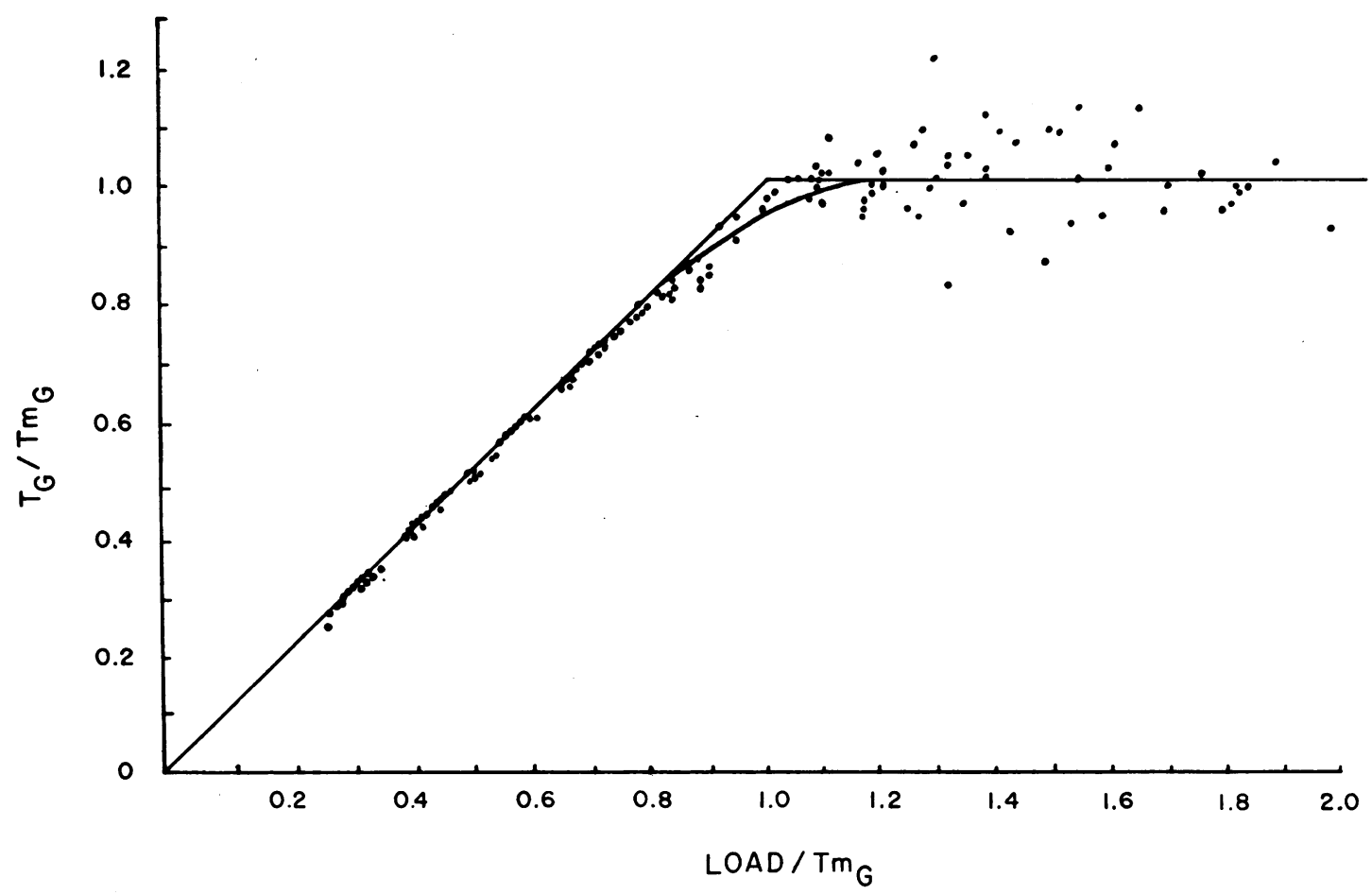

FIGURE 1 Composite glucose titration curve of 14 normal young men, constructed as per text of paper. 
we administered glucose loads as a $30 \%$ solution of glucose in water at increasing pump speeds, using a separate Bowman infusion pump. Arterial samples were drawn via an indwelling arterial needle into heparinized syringes at appropriate intervals during each collection period; $12-16$ periods of $12-15$ min duration were measured in all subjects. Inulin was yeasted twice with fresh baker's yeast and then measured by the method of Schreiner (12). Glucose was measured, with glucose oxidase, by the technique of Washko and Rice (13). To ascertain the presence of isolated or multiple tubular excretory abnormalities, phosphorus was measured by the method described by Fiske and Subbarow (14) and uric acid by the uricase method of Feichtmeir and Wrenn (15).

We constructed smoothed titration curves as described by Smith (7), plotted the rate of reabsorbed glucose $\left(\mathrm{T}_{G}\right) / \mathrm{Tm}_{\mathrm{G}}$ against the load of glucose filtered (load)/ $\mathrm{Tm}_{\mathrm{a}}$ for each individual period, and drafted the individual curves by visual approximation. Splay for each individual patient was determined from the deviation of the curve of approximation drawn for each subject from the theoretical reabsorption line. The average titration curve for all normal, nonglucosuric subjects was constructed in the same manner and is reproduced in Fig. 1: the comparative groups are graphed in Figs. 2-5.

Statistical analysis, using approximate $t$ tests, was performed according to Steel and Torrie (16) to compare normal and glucosuric groups.

\section{RESULTS}

Normal subjects. Data from the different groups of subjects are tabulated separately in Tables I, II, and III. The normal control group (Table I) of nonglucosuric young men had corrected, mean glomerular filtration rates (GFR) of $127 \mathrm{ml} / \mathrm{min}$, not significantly different from our larger control group of 31 men whose average GFR was $124 \pm$ $12 \mathrm{ml} / \mathrm{min}$. The mean $\mathrm{Tm}_{\mathrm{G}}$ measured as the average of three or more consecutive periods after achievement of a stable value at satisfactory load/ $\mathrm{Tm}_{\mathrm{G}}$ level is $325 \pm 36 \mathrm{mg} / \mathrm{min}$ (corrected to 1.73 $\mathrm{m}^{2}$ body surface area). The latter figure is in reasonable accord with Smith's published values of $375 \pm 79.7 \mathrm{mg} / \mathrm{min}$ in a larger group of men. The mean point of splay from the theoretical reabsorptive line, as estimated from the individual curves, is $0.83 \pm 0.04$. This defines a much smaller splay than previously published data on normal subjects has indicated $(7,11)$. Although load to $\mathrm{Tm}_{G}$ ratios in subjects $3,8,9$, and 10 of Table $I$ are in the range of $1.17-1.27$, collection and analysis of additional periods as part of another study, beyond the periods used for calculation of $\mathrm{Tm}_{G}$, indicated a stable reabsorptive rate at much higher load to $\mathrm{Tm}_{\mathrm{g}}$ ratios; this gave assurance that the maximal reabsorptive rate was indeed reached. $\mathrm{Tm}_{\mathrm{G}}$ corrected for body surface area and $100 \mathrm{ml}$ of GFR yield a mean value of $234 \pm 21 \mathrm{mg}$ ( 1 $\mathrm{SD}) / \mathrm{min}$.

TABLE I

Tabulation of Functional Data in Normal Subjects

\begin{tabular}{|c|c|c|c|c|c|c|}
\hline Patient & Age & $\begin{array}{c}\text { CInulin corrected } \\
\text { to } 1.73 \mathrm{~m}^{2}\end{array}$ & $\begin{array}{c}\mathrm{T} \mathrm{m}_{\mathrm{G}} \text { corrected } \\
\text { to } 1.73 \mathrm{~m}^{2}\end{array}$ & $\begin{array}{c}\mathrm{Tm}_{\mathrm{G}} / 1.73 \mathrm{~m}^{2} \\
\text { per } 100 \mathrm{ml} \\
\text { GFR }\end{array}$ & Splay point & Load $/ \mathrm{Tm}_{\mathrm{G}}$ \\
\hline 1 & 20 & 133 & 331 & 258 & & 1.84 \\
\hline 2 & 26 & 94 & 290 & 249 & & 1.76 \\
\hline 3 & 20 & 132 & 326 & 222 & 0.83 & 1.19 \\
\hline 4 & 18 & 138 & 353 & 257 & 0.80 & 1.84 \\
\hline 5 & 24 & 115 & 325 & 264 & 0.81 & 1.36 \\
\hline 6 & 18 & 118 & 306 & 235 & 0.81 & 1.40 \\
\hline 7 & 19 & 140 & 314 & 225 & 0.81 & 1.61 \\
\hline 8 & 18 & 120 & 331 & 249 & 0.80 & 1.27 \\
\hline 9 & 18 & 130 & 276 & 182 & 0.91 & 1.18 \\
\hline 10 & 19 & 106 & 290 & 222 & 0.82 & 1.17 \\
\hline 11 & 17 & 105 & 270 & 223 & 0.80 & 1.66 \\
\hline 12 & 20 & 117 & 297 & 237 & 0.88 & 1.76 \\
\hline 13 & 22 & 149 & 375 & 239 & 0.80 & 1.93 \\
\hline 14 & 23 & 147 & 356 & 213 & 0.92 & 1.32 \\
\hline 15 & 24 & 140 & 390 & 250 & 0.86 & 2.49 \\
\hline 16 & 28 & 149 & 370 & 225 & 0.79 & 1.65 \\
\hline Mean & & 127 & 325 & 234 & 0.83 & \\
\hline $1 \mathrm{SD}$ & & \pm 17 & \pm 36 & \pm 21 & \pm 0.04 & \\
\hline
\end{tabular}


TABLE II

Tabulation of Glucosuric, Nonnephritic Young Men Studied by Glucose Titrations

\begin{tabular}{|c|c|c|c|c|c|c|c|c|c|}
\hline Patient & Age & $\begin{array}{l}\text { CInulin/ } \\
1.73 \mathrm{~m}^{2}\end{array}$ & $\mathrm{Tm}_{\mathrm{G}} / 1.73 \mathrm{~m}^{2}$ & $\begin{array}{c}\text { Tma } / 1.73 \mathrm{~m}^{2} \\
\text { per } 100 \mathrm{ml} \\
\text { GFR }\end{array}$ & Splay point & $\begin{array}{c}\text { Load/ } \\
\text { Tma }\end{array}$ & $\begin{array}{c}\text { Glucosuria } \\
\text { pattern }\end{array}$ & $\begin{array}{l}\text { Duration } \\
\text { glucosuria }\end{array}$ & $\begin{array}{l}\text { 24-hour } \\
\text { glucose } \\
\text { excretion }\end{array}$ \\
\hline & & & & & & & & $y r$ & \\
\hline 1 & 28 & 127 & 233 & 166 & 0.26 & 2.09 & Consistent & 22 & - \\
\hline 2 & 18 & 110 & 135 & 123 & 0.66 & 2.87 & Consistent & 3 & $14 \mathrm{~g}$ \\
\hline 3 & 30 & 132 & 208 & 147 & 0.73 & 1.79 & Consistent & 10 & - \\
\hline 4 & 33 & 96 & 132 & 137 & 0.72 & 4.14 & Consistent & 16 & $4.9 \mathrm{~g}$ \\
\hline 5 & 17 & 110 & 144 & 111 & 0.53 & 2.55 & Consistent & 12 & $25 \mathrm{~g}$ \\
\hline 6 & 25 & 92 & 174 & 189 & 0.67 & 3.81 & Consistent & 8 & $2.7 \mathrm{~g}$ \\
\hline Mean & & 111 & 171 & 146 & 0.60 & & & & \\
\hline $1 \mathrm{SD}$ & & \pm 16 & \pm 42 & \pm 29 & \pm 0.18 & & & & \\
\hline Significance & & & $P<0.001$ & $P<0.001$ & $P<0.05$ & & & & \\
\hline 7 & 26 & 121 & 296 & 231 & & 2.65 & Occasional & - & $2.3 \mathrm{~g}$ \\
\hline 8 & 24 & 127 & 450 & 343 & 0.48 & 1.93 & Occasional & - & $900^{\circ} \mathrm{mg}$ \\
\hline 9 & 31 & 127 & 456 & 335 & 0.18 & 2.58 & Consistent & 13 & - \\
\hline 10 & 32 & 113 & 443 & 366 & 0.53 & 1.73 & Occasional & 5 & - \\
\hline 11 & 24 & 136 & 405 & 254 & 0.84 & 1.55 & Occasional & 一 & - \\
\hline 12 & 27 & 110 & 269 & 204 & 0.76 & 2.22 & Occasional & - & - \\
\hline 13 & 23 & 112 & 316 & 239 & 0.66 & 1.77 & Occasional & - & $900 \mathrm{mg}$ \\
\hline 14 & 22 & 180 & 501 & 290 & 0.45 & 2.15 & Consistent & - & - \\
\hline Mean & & 128 & 392 & 283 & 0.56 & & & & \\
\hline 1 SD & & \pm 23 & \pm 86 & \pm 60 & \pm 0.24 & & & & \\
\hline \multicolumn{3}{|c|}{ Significance (see normal subjects) } & NS* & NS & $P<0.01$ & & & & \\
\hline
\end{tabular}

* NS, not significant.

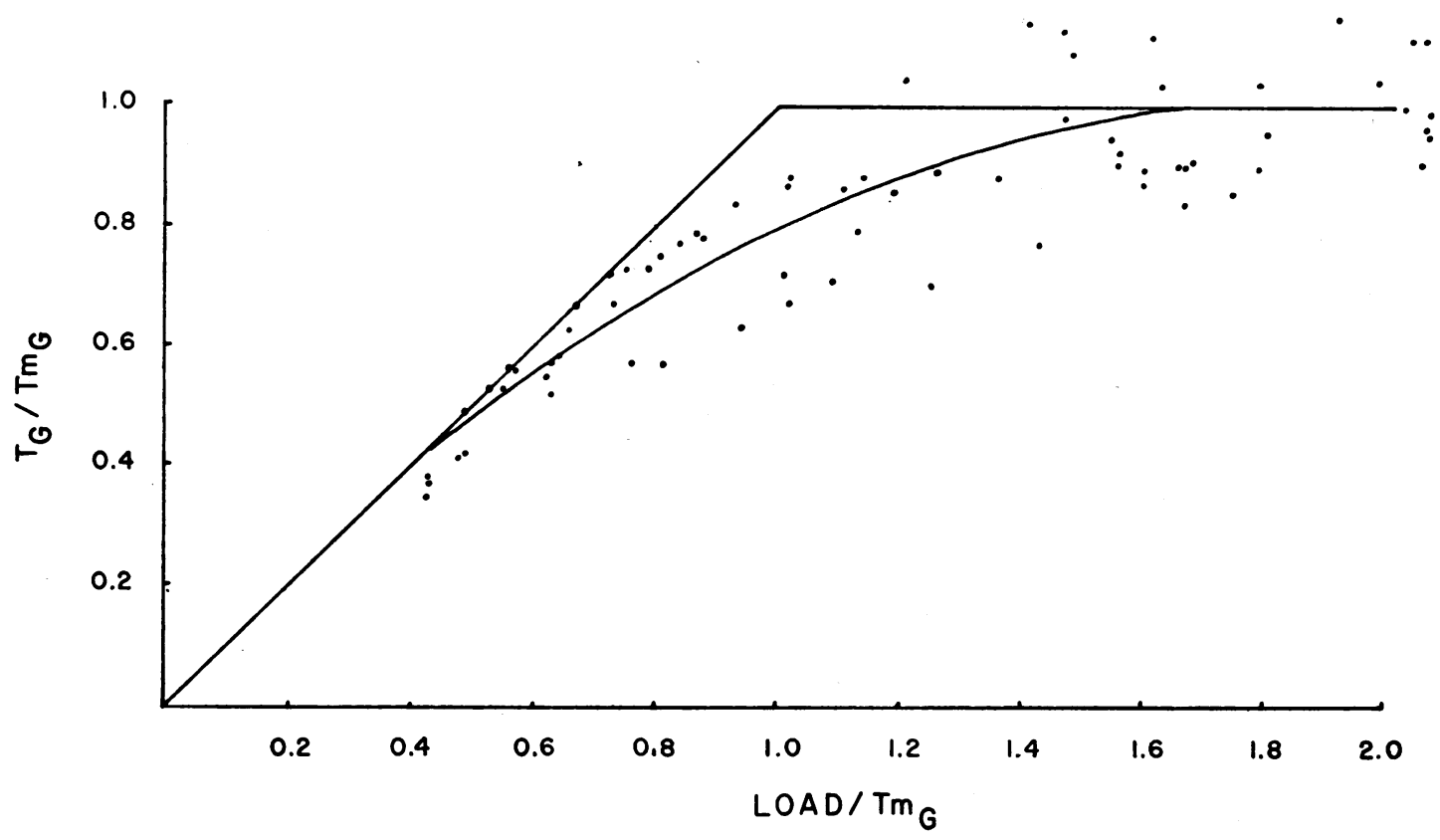

FIGURE 2 Composite glucose titration curve of glucosuric, nonnephritic, young men with subnormal Tma. 


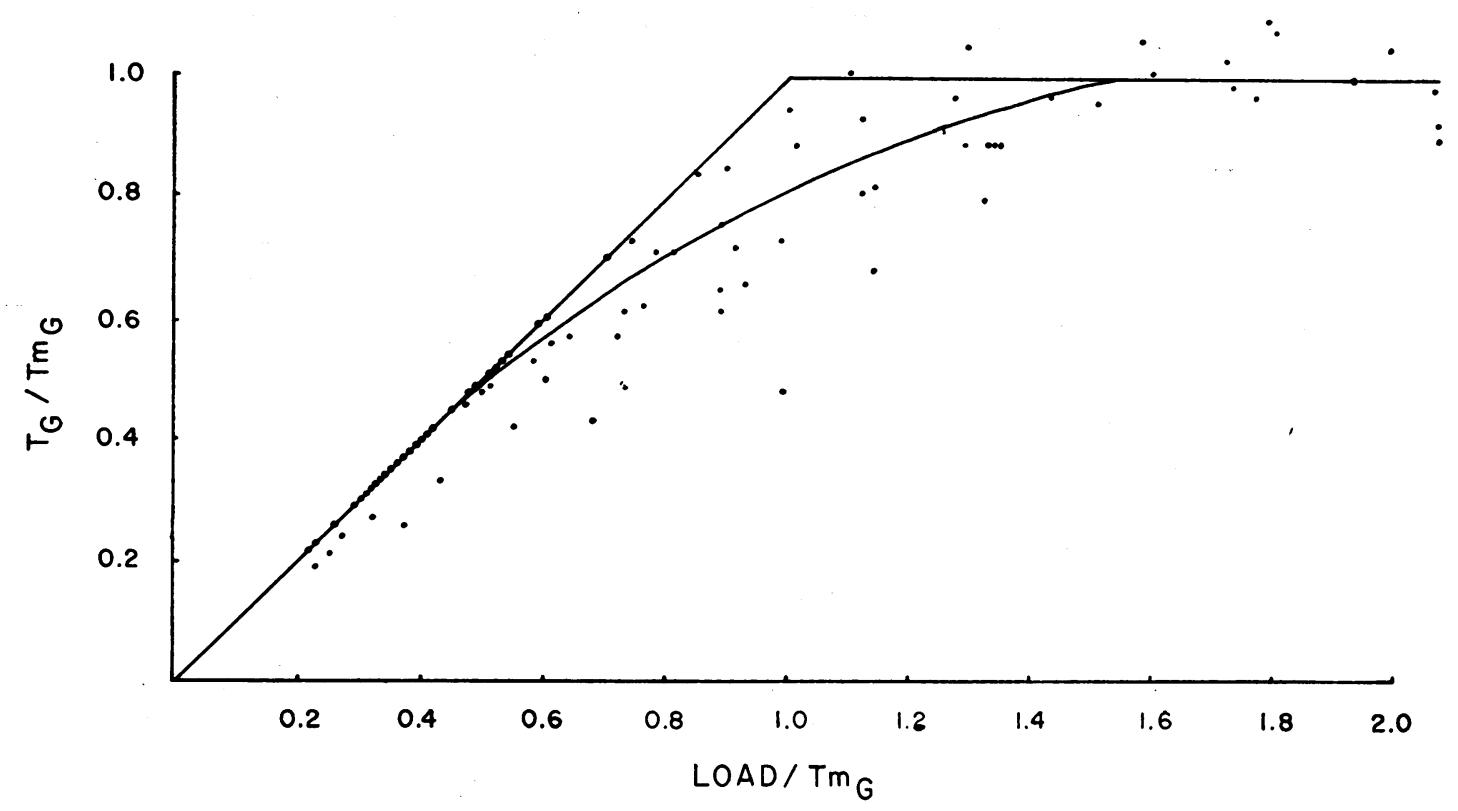

FIGURE 3 Composite glucose titration curve of glucosuric, nonnephritic, young men with normal Tma.

Glucosuric nonnephritic subjects. Measured cantly lower than normal $\mathrm{Tm}_{\mathrm{G}}$ displaying a mean GFR did not differ in these 14 subjects from the $\mathrm{Tm}_{\mathrm{G}}$ of $171 \pm 42 \mathrm{mg} / \mathrm{min}(P<0.001)$. All six control group in any significant manner. As indicated in Table II, however, 6 of the 14 patients of the glucosuric patients with subnormal $\mathrm{Tm}_{\mathrm{G}}$ had an abnormal splay to their titrations, with a mean in this group (patients 1-6) manifested signifi- splay point of $0.60 \pm 0.18(P<0.05$, Fig. 2).

TABLE III

Tabulation of Renal Functional and Clinical Characteristics During Glucose Titration of 10 Chronic Nephritic Subjects

\begin{tabular}{|c|c|c|c|c|c|c|c|c|c|c|}
\hline Patient* & Age & Sex & $\begin{array}{l}\text { CInulin } \\
\text { corrected } \\
\text { to } 1.73 \mathrm{~m}^{2}\end{array}$ & $\begin{array}{l}\text { TmG cor- } \\
\text { rected to } \\
1.73 \mathrm{~m}^{2}\end{array}$ & $\begin{array}{c}\text { Tmg } / 1.73 \mathrm{~m}^{2} \\
\text { per } 100 \mathrm{ml} \\
\text { GFR }\end{array}$ & Splay point & $\begin{array}{c}\text { Load/ } \\
\text { Tma }\end{array}$ & $\begin{array}{c}\text { Blood } \\
\text { urea } \\
\text { nitrogen }\end{array}$ & $\begin{array}{l}\text { Glu- } \\
\text { cos- } \\
\text { uria }\end{array}$ & $\begin{array}{l}\text { Pro- } \\
\text { tein- } \\
\text { uria }\end{array}$ \\
\hline & & & & & & & & $\begin{array}{c}\mathrm{mg} / \\
100 \mathrm{ml}\end{array}$ & & $\mathrm{g} / 24 \mathrm{hr}$ \\
\hline 1 & 26 & $\mathbf{M}$ & 138 & 349 & 214 & 0.80 & 2.18 & 19 & + & 0.2 \\
\hline 2 & 27 & $\mathbf{M}$ & 125 & 276 & 226 & 0.83 & 4.30 & 18 & + & 2.0 \\
\hline 3 & 29 & $\mathbf{M}$ & 105 & 429 & 313 & 0.38 & 1.60 & 20 & + & 5.0 \\
\hline 4 & 35 & $\mathbf{F}$ & 98 & 334 & 342 & 0.75 & 1.88 & 18 & 0 & 3.5 \\
\hline 5 & 45 & $\mathrm{~F}$ & 66 & 346 & 552 & 0.64 & 2.61 & 26 & + & 6.0 \\
\hline 6 & 27 & $\mathbf{M}$ & 44 & 232 & 442 & 0.66 & 1.60 & 32 & + & 5.0 \\
\hline 7 & 35 & $\mathrm{~F}$ & 38 & 160 & 516 & 0.46 & 1.75 & 36 & + & 4.0 \\
\hline 8 & 45 & $\mathbf{F}$ & 35 & 77 & 266 & 0.70 & 3.60 & 28 & + & 2.0 \\
\hline 9 & 26 & $\mathbf{M}$ & 27 & 130 & 491 & 0.20 & 2.28 & 40 & + & 6.0 \\
\hline 10 & 48 & $\mathbf{M}$ & 13 & 66 & 411 & 0.16 & 2.11 & 42 & + & 3.5 \\
\hline \multicolumn{4}{|l|}{ Mean } & 240 & 377 & 0.56 & & & & \\
\hline \multicolumn{4}{|c|}{$1 \mathrm{SD}$} & \pm 127 & \pm 123 & \pm 0.24 & & & & \\
\hline \multicolumn{4}{|c|}{ Significance (see normal subjects) } & NS & $P<0.01$ & $P<0.01$ & & & & \\
\hline
\end{tabular}

* All patients had clinical diagnosis of chronic glomerulonephritis confirmed by percutaneous renal biopsy. 


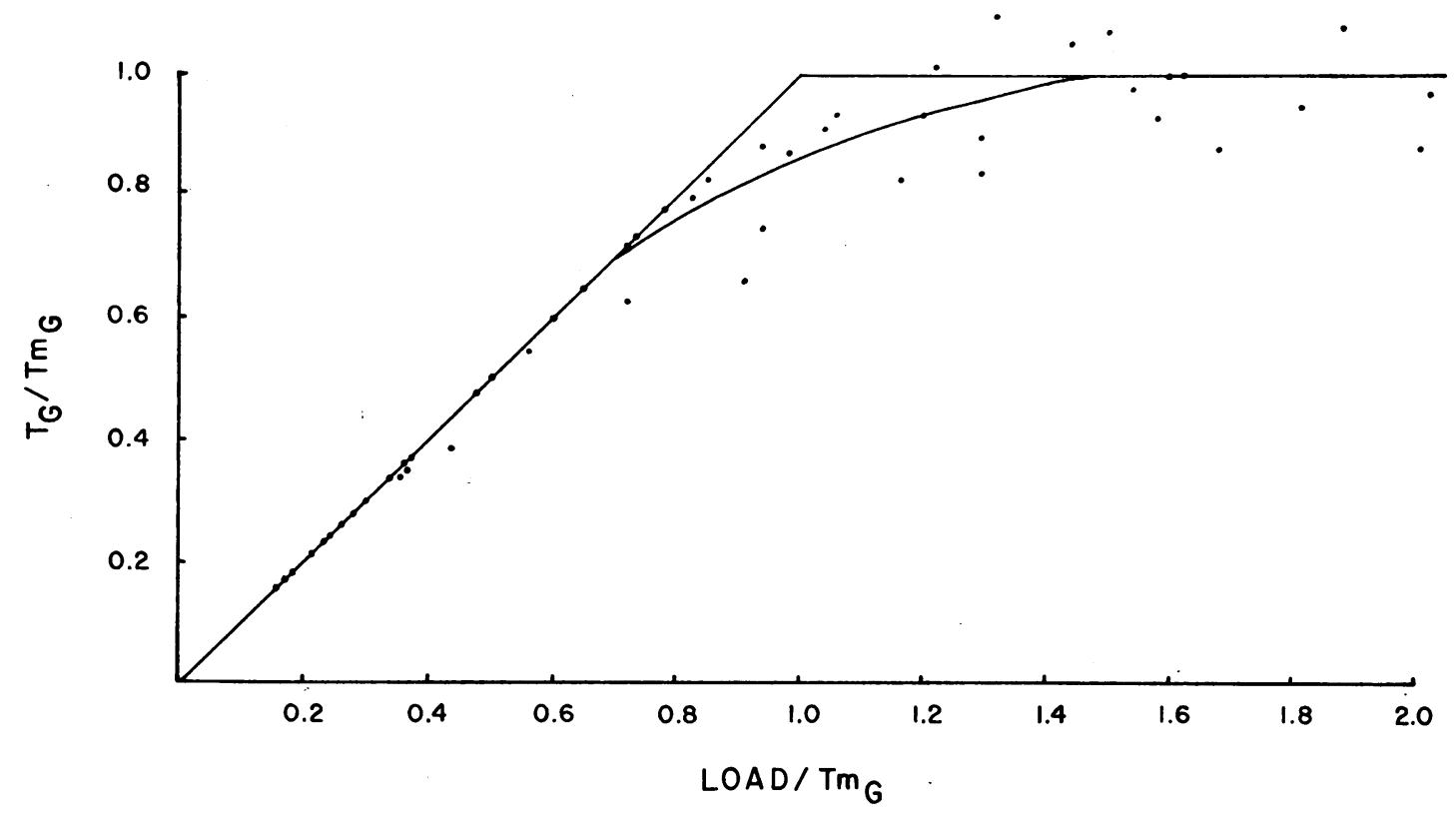

FIGURE 4 Composite glucose titration curve of four patients with chronic glomerulonephritis and glomerular filtration rates in excess of $90 \mathrm{ml} / \mathrm{min}$.

The remaining eight glucosuric patients (7-14) had normal values for $\mathrm{Tm}_{\mathrm{G}}$ (mean $392 \pm 86 \mathrm{mg}$ / min, $P>0.05$ ), but demonstrated a similarly abnormal splay in six of the seven who underwent titration (mean $0.56 \pm 0.24, P<0.01$, Fig. 3 ).
We made an arbitrary division in Table II to allow separate analysis of glucosuric subjects with subnormal maximal reabsorptive rates and the group with normal maximal reabsorptive rates. One can discern that consistent glucosuria usually

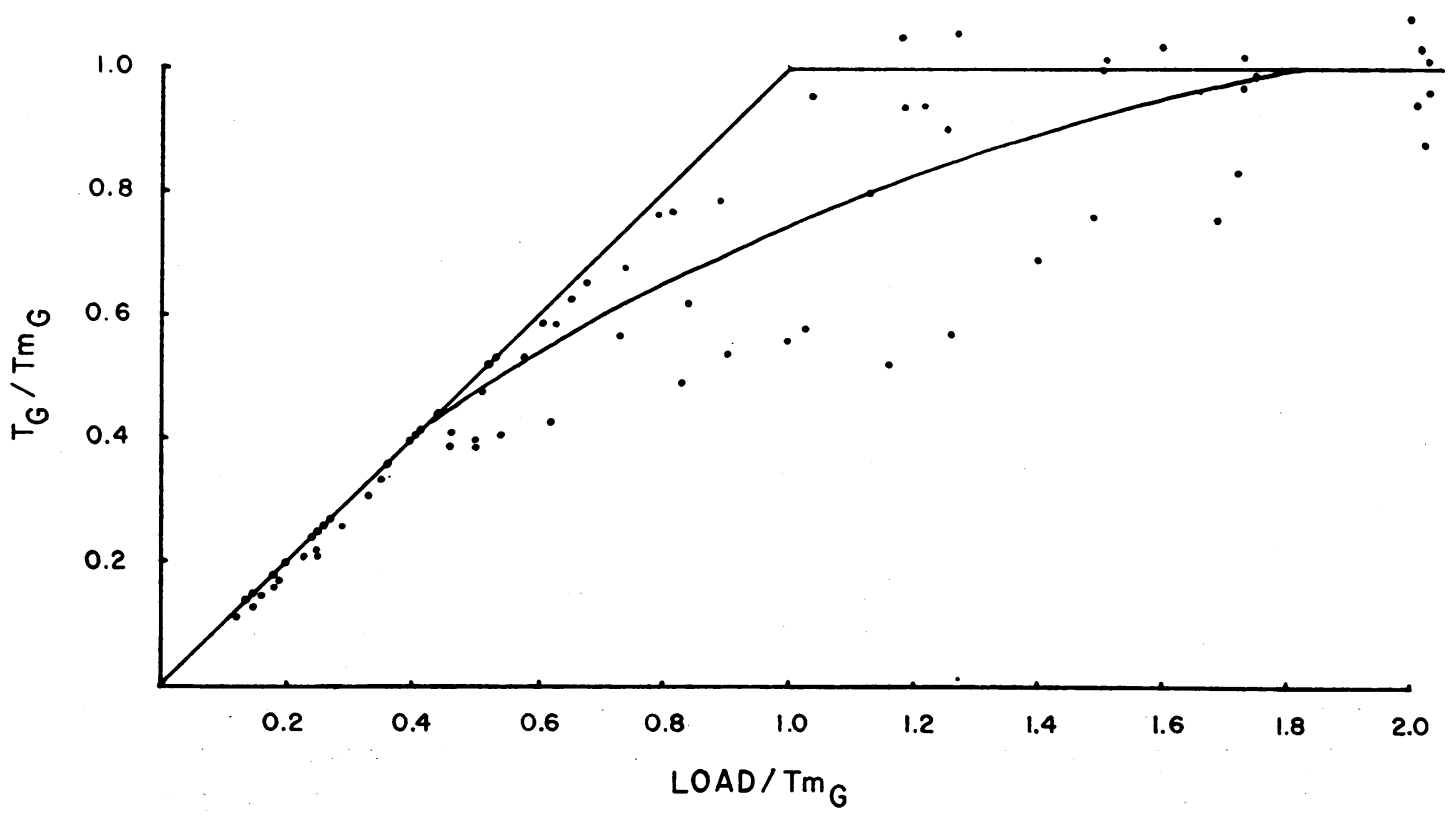

FIGURE 5 Composite glucose titration curve of six patients with chronic glomerulonephritis and glomerular filtration rates less than $90 \mathrm{ml} / \mathrm{min}$. 
occurred in subjects with subnormal $\mathrm{Tm}_{\mathrm{G}}$ and (or) marked abnormality of titration splay. Phosphorus clearances and uric acid clearances for these patients were not significantly different from normal, confirming that other renal tubular abnormalities were not present. None had an abnormal serum electrolyte pattern suggestive of acidosis or other metabolic derangements.

Patients with chronic nephritis and normal glucose tolerance tests. The 10 patients in this group (Table III) differed in some respects from the foregoing groups. 4 of the 10 were females and 2 of these were edematous at the time of the study; 7 patients had subnormal GFR. Inasmuch as the group under study was so diverse as to its renal function, the mean $\mathrm{Tm}_{\mathrm{G}}$ of $240 \mathrm{mg} / \mathrm{min}$ was not surprising, and a wide standard deviation was observed. However, it is important to note that the individual $\mathrm{Tm}_{\mathrm{G}}$ values corrected to $1.73 \mathrm{~m}^{2}$ body surface area and $100 \mathrm{ml}$ of GFR were substantially greater than normal in 8 of the 10 nephritic subjects. The only two normal values for the latter were found in patients 1 and 2 of Table III : two male nephritics who had normal GFR. Conversely, the same two subjects were the only nephritics who had a demonstrably normal splay to their titration curves. Figs. 4 and 5 allow comparison of average titration curves of nephritic subjects with near normal and markedly abnormal GFR.

\section{DISCUSSION}

Generally speaking, glucosuria should occur whereever the filtered load of glucose exceeds the point of splay of a titration curve or exceeds the maximal renal reabsorptive rate for glucose. As used in this discussion, the word "threshold" connotes the point of splay, where the relationship $T_{G} / \mathrm{Tm}_{G}$ relative to load/ $\mathrm{Tm}_{\mathrm{G}}$ deviates significantly from unity.

Establishment of a range of titration curves seems a necessary prerequisite for interpretation of normal renal handling of glucose loads. Despite the necessarily approximate nature of determination of the point of splay from the line of unity, the present studies indicate an unexpectedly high "threshold" in normal young men. It is of interest that the lowest point of splay in the titration curves of 14 normal young men was 0.79 .

Review of published glucose titration data $(7$, 11 ) indicates that most have been derived in older subjects and present scant material from normal young men. The precise applicability of information from studies of older subjects is uncertain, inasmuch as Miller, McDonald, and Shock (17) have documented significant decline in GFR and $\mathrm{Tm}_{\mathrm{G}}$ with advancing age. Glucose titrations reported by Christensen (18) as performed in young, nonpregnant women indicated average values for splay points similar to our data.

Such comparative information allows more reasonable examination of the titration characteristics of a group of glucosuric young men of similar age range. Our results indicate clearly that there are two principal types of nondiabetic glucosuria. The first is characterized by the presence of a low $\mathrm{Tm}_{\mathrm{G}}$ and also an abnormal splay with respect to that maximal reabsorptive rate. The second is characterized by an almost uniformly subnormal splay but a normal $\mathrm{Tm}_{\mathrm{G}}$. One documented glucosuric subject (patient 11, Table II) fulfilled neither generalization.

It might seem appropriate to conclude from our examinations that the classic renal glucosuric, described by Marble and others, is one whose maximal reabsorptive capacity for glucose is subnormal, and concomitantly has a low threshold even for that $\mathrm{Tm}_{\mathrm{G}}$. However, it should be noted that patients 9 and 14 of Table II, who had normal measured values for $\mathrm{Tm}_{\mathrm{G}}$ had remarkably low splay values and a history of consistent glucosuria. Obviously, then, in these latter subjects the subnormal splay, or low threshold, was the primary determinant of the appearance of glucosuria despite the normal $\mathrm{Tm}_{\mathrm{G}}$. Hence, a subnormal $\mathrm{Tm}_{\mathrm{G}}$ is not necessarily a prerequite for consistent glucosuria.

This concept has been suggested by Reubi (19) and Mudge (20) from studies of smaller numbers of patients. Some of the patients with an abnormal splay but normal $\mathrm{Tm}_{G}$, studied by these latter investigators, had hypertension and (or) abnormally low para-aminohippurate clearances. For this reason, they expressed uncertainty as to whether acquired renal disease might be responsible for the glucosuria in their patients with glucosuria and normal $\mathrm{Tm}_{\mathrm{G}}$. However, no significant evidence of disease has been found in our patients.

Our few data on quantitative daily excretion of glucose (Table II) suggest that renal glucosurics with low maximal reabsorptive rates excrete a 
greater amount of glucose than the glucosurics whose titration curves are characterized by the splay deviation but whose $\mathrm{Tm}_{\mathrm{G}}$ is normal. This emphasizes the suggestion that splay determines the threshold for appearance of recognizable glucosuria whereas the maximum reabsorptive rate is the usual determinant of the magnitude of measured glucosuria.

Examination of the nephritic patients, all of whom had normal glucose tolerance tests and all but one of whom (patient 4, Table III) was glucosuric, is also of interest in the present context. Only two of these patients had normal splay; these latter were subjects with normal GFR. Although the measured $\mathrm{Tm}_{\mathrm{G}}$ necessarily displayed a wide range, it tended to be preserved disproportionately in the face of declining renal function. The net result is that correction of the measured individual glucose $\mathrm{Tm}$ of the nephritic patient to body surface area and GFR proportionate to the nonnephritic subjects indicates a supranormal reabsorptive rate per nephron unit in all the nephritic patients with compromised renal function.

The frequency of the observed glucosuria in the chronic nephritic patients probably is conditioned by the same factor noted in the nonnephritic patients; namely, the high incidence of abnormal splay. The latter probably indicates a greater than normal nonhomogeneity of nephron units among the residual functioning nephrons.

Several alterations of normal pathophysiological relationships may be implicated in the latter. These include changes in perfusion to cortical nephrons and alterations of structure of proximal tubular epithelial cells due to hypertrophy, dilatation, and lipid infiltration. Other factors to be considered are general depression of proximal tubular reabsorptive activity and passive back diffusion of glucose into tubules through an anatomically disrupted architecture at higher blood sugar levels.

Although our data do not allow us to choose critically between such diverse possibilities, there is experimental support for some of them. Abnormalities of para-aminohippurate extraction have been documented in advanced nephritis by Bradley, Bradley, Tyson, Curry, and Blake (21), and in shock associated with marked decrease in GFR by Lauson, Bradley, and Cournand (22), indicating that alteration of tubular perfusion pat- terns may occur. Microdissection of whole nephrons from kidneys from patients with chronic nephritis indicated frequent occurrence of atrophic nephrons in association with dilated and hyperplastic nephrons, some of which were lipid-laden and grossly distorted $(23,24)$. Similarly, a discrete, spotty, anatomic lesion of proximal tubules has been invoked by Monasterio, Oliver, Muiesan, Pardelli, Marinozzi, and MacDowell as an explanation for the observed splay in their subjects with true renal diabetes (25).

Our results stand in contrast to the observations of Rieselbach, Shankel, Slatopolsky, Lubowitz, and Bricker (26) in man and Shankel, Robson, and Bricker in the rat (27) in two respects. In the former study, no abnormality of splay was detected until advanced renal insufficiency supervened. This can be reconciled with our data inasmuch as the splay of our nephritic patients with more and less advanced renal insufficiency was quite comparable to theirs and clearly different from the group of normal men $(P<0.01)$ reported herein. Secondly, $\mathrm{Tm}_{\mathrm{G}}$ corrected to proportionate body surface area and GFR in nephritic patients of this series was significantly greater than normal $(P<$ $0.01)$. Although Rieselbach et al. implied that the nephritic patients they studied showed no such relative increase in glucose reabsorption per nephron, the mean inulin clearance/ $\mathrm{Tm}_{\mathrm{G}}$ ratio of their patients was 0.305 , comparable to the value of this ratio for nephritic patients in this series $(0.285$, $P>0.05)$ and significantly different from normal subjects $(0.391, P<0.01)$. That no such adaptation was observed in experimentally diseased kidneys of rats (27), may be due to the abrupt onset of the lesion and the relatively short duration allowed for adaptation. Oliver (24) has suggested that an intermittency of disease is most advantageous for optimal development of maximal architectural adaptation. There can be no doubt, however, that as GFR declines, a greater osmolar clearance per unit GFR does occur and conceivably might exaggerate splay characteristics of the diseased kidney $(27,28)$.

Despite the indication from our data that an abnormal splay is the most frequent abnormality and likeliest explanation for either consistent or occasional glucosuria in nondiabetic subjects, with and without nephritis, one nonnephritic subject (patient 11, Table II) and two nephritic subjects 
(patients 1 and 2, Table III) had both normal splay patterns and $\mathrm{Tm}_{\mathrm{G}}$. An explanation for their glucosuria cannot be made to our complete satisfaction.

It is suspected that the glucosuria in these subjects may have been noted because of factors which are not often mentioned but which should be considered: the sensitivity of screening tests, the relative differences of arterial and venous glucose concentrations, and the contribution of a high GFR. Commercially prepared strips of paper impregnated with glucose oxidase are widely used for mass screening tests of urine. Although clearly demonstrated by O'Sullivan, Kantor, and Wilkerson (29), it is not recognized widely that these strips are exquisitely sensitive to relatively low concentrations of urinary glucose. Such concentrations may be detected in many otherwise normal people after a usual meal, as indicated by Fine (3).

A relatively modest and transient rise of arterial glucose concentration in association with a high GFR and normal splay can result in a glucose load which exceeds a "normal" threshold and cause glucosuria, despite normal glucose tolerance tests.

It is concluded that there are two general types of glucosuric nondiabetic subjects: (a) people with a low $\mathrm{Tm}_{\mathrm{g}}$ and abnormal splay, and $(b)$ people with normal $\mathrm{Tm}_{\mathrm{g}}$ and abnormal splay. Glucosuria occurring during the course of chronic renal disease usually is a manifestation of the latter type of mechanism.

\section{ACKNOWLEDGMENT}

The assistance of Mr. Alton Rahe, Biomedical Statistician, School of Aviation Medicine, Brooks Air Force Base, is gratefully acknowledged.

\section{REFERENCES}

1. Marble, A. 1959. Non-diabetic mellituria. In Treatment of Diabetes Mellitus. E. P. Joslin, H. F. Root, P. White, and A. Marble, editors. Lea \& Febiger, Philadelphia. 717.

2. Peel, A. A. F., and M. W. Peel. 1941. Glycosuria in cruits. Glasgow Med.J. 135: 141.

3. Fine, J. 1965. Glucose content of normal urine. Brit. Med. J. 1: 1209.

4. Hawkins, J. A., E. MacKay, and D. D. Van Slyke. 1929. Glucose excretion in Bright's disease. J. Clin. Invest. 8: 107.

5. Donato, L., and G. Turchetti. 1955. Renal glycosuria in pregnancy. Acta Med. Scand. 152: 223.
6. Shannon, J. A., and S. Fisher. 1938. The renal tubular reabsorption of glucose in the normal dog. $A m$. J. Physiol. 122: 765 .

7. Smith, H. W. 1943. Application of saturation methods to the study of glomerular and tubular function in the human kidney. In Lectures on the Kidney. University Extension Division, University of Kansas, Lawrence. 83

8. Burgen, A. S. V. 1956. A theoretical treatment of glucose reabsorption in the kidney. Can. J. Biochem. Physiol. 34: 466.

9. Oliver, J., and M. MacDowell. 1961. The structural and functional aspects of the handling of glucose by the nephrons and the kidney and their correction by means of structural-functional equivalents. J. Clin. Invest. 40: 1093.

10. Bradley, S. E., J. H. Laragh, H. O. Wheeler, M. MacDowell, and J. Oliver. 1961. Correlation of structure and function in the handling of glucose by the nephrons of the canine kidney. J. Clin. Invest. 40: 113.

11. Letteri, J. M., and L. G. Wesson, Jr. 1965. Glucose titration curves as an estimate of intrarenal distribution of glomerular filtrate in patients with congestive heart failure. J. Lab. Clin. Med. 65: 387.

12. Schreiner, G. E. 1950. Determination of inulin by means of resorcinol. Proc. Soc. Exptl. Biol. 74: 117.

13. Washko, M. E., and E. W. Rice. 1961. Determination of glucose by an improved enzymatic procedure. Clin. Chem. 7: 542.

14. Fiske, C. H., and Y. Subbarow. 1925. The colorimetric determination of phosphorus. J. Biol. Chem. 66: 375 .

15. Feichtmeir, T. V., and H. T. Wrenn. 1955. Direct determination of uric acid using uricase. Am. J. Clin. Pathol. 25 : 833.

16. Steel, R. G. D., and J. H. Torrie. 1960. Principles and procedures of statistics. McGraw-Hill Book Company, New York. 67.

17. Miller, J. H., R. K. McDonald, and N. W. Shock. 1952. Age changes in the maximal rate of renal tubular reabsorption of glucose. J. Gerontol. 7: 196.

18. Christensen, P. J. 1958. Tubular reabsorption of glucose during pregnancy. Scand. J. Clin. Lab. Invest. 10: 364 .

19. Reubi, F. C. 1954. Glucose titration in renal glycosuria. In Ciba Foundation symposium on the Kidney. A. A. G. Lewis and G. E. W. Wolstenholme, editors. Little, Brown and Company, Boston. 96.

20. Mudge, G. H. 1956. Disorders of renal tubular function. Am. J. Med. 20: 448.

21. Bradley, S. E., G. P. Bradley, C. J. Tyson, J. J. Curry, and W. D. Blake. 1950. Renal function in renal diseases. Am. J. Med. 9: 766.

22. Lauson, H. D., S. E. Bradley, and A. Cournand. 1944. The renal circulation in shock. J. Clin. Invest. 23: 381.

23. Oliver, J. 1939. Architecture of the Kidney in Chronic Bright's Disease. Hoeber-Harper Bros., New York. 102. 
24. Oliver, J. 1944. New directions in renal morphology. A method, its results and its future. In The Harvey Lectures. Academic Press, Inc., New York. 102.

25. Monasterio, G., J. Oliver, G. Muiesan, G. Pardelli, V. Marinozzi, and M. MacDowell. 1964. Renal diabetes as a congenital tubular dysplasia. Am. J. Med. 37: 44.

26. Rieselbach, R. E., S. W. Shankel, E. Slatopolsky, H. Lubowitz, and N. S. Bricker. 1967. Glucose titration studies in patients with chronic progressive renal disease. J. Clin. Invest. 46: 157.
27. Shankel, S. W., A. M. Robson, and N. S. Bricker. 1967. On the mechanism of splay in the glucose titration curve in advanced renal disease in the rat. $J$. Clin. Invest. 46: 164.

28. Callaway, C. P. 1950. Unilateral renal glycosuria in association with diabetes mellitus and chronic pyelonephritis. Ann. Internal. Med. 33: 243.

29. O'Sullivan, J. B., N. Kantor, and H. L. C. Wilkerson. 1962. Comparative value of tests for urinary glucose. Diabetes. 11: 53. 